Artículo

\title{
La naturaleza afectiva de la libertad
}

\section{Federica Gregoratto*}

*UNIVERSitÄt St. GALLEN

\section{Resumen:}

Este artículo sostiene que el aspecto crítico y emancipatorio de la noción hegeliana de libertad necesita más investigación y elaboración. El proceso a través del cual los individuos y las comunidades se vuelven libres solo puede dilucidarse a cabalidad cuando tenemos en cuenta la dimensión sensual, somática y afectiva. La libertad humana implica no solo actividad, sino al mismo tiempo momentos de pasividad. El argumento se desarrolla en tres pasos: una reconstrucción de la idea de libertad social; una revisión del argumento de Adorno contra la concepción kantiana de la autonomía, aplicada a la noción de libertad social de Hegel, destacando los componentes impulsivos o afectivos de la libertad y reforzando así lo que puede considerarse su naturaleza negativa; y la revisión de algunos pasajes de la novela Otro país de James Baldwin.

Palabras clave: Libertad social; Afectos; Dewey; Hegel; Adorno.

\begin{abstract}
:
This article argues that the critical and emancipatory aspect of the Hegelian notion of freedom needs more research and elaboration. The process by means of which individuals as well as communities become free can only be fully understood if we take into account the sensuous, somatic, and passionate dimension. Human freedom implied not only activity, but at the same time moments of passivity. The argument unfolds in three steps: a reconstruction of the idea of social freedom; a revision of Adorno's argument against the Kantian conception of autonomy, applied to Hegel's notion of social freedom and highlighting the impulsive, passionate concepts of freedom and thus reinforcing what can be considered its negative nature; and the revision of some passages of James Baldwin's novel Another Country.
\end{abstract}


Keywords: Social Freedom; Passions; Dewey; Hegel; Adorno.

Recibido: 13 de noviembre de 2019

Aceptado: 25 de diciembre de 2019

No puedo ser libre en soledad. Mis semejantes también deben ser libres para permitirme y ayudarme a ser libre. Deben existir condiciones sociales objetivas que permitan y garanticen la libertad de todos potencialmente. Pero ¿qué pasa si estas condiciones sociales son deficientes o faltantes? ¿Cómo liberarse de una condición de falta de libertad? Estos son algunos de los temas centrales y más espinosos que preocupan a los filósofos sociales en deuda con el pensamiento de Hegel, especialmente a aquellos afiliados a la tradición de la teoría social crítica de la Escuela de Frankfurt, así como también a John Dewey. En este artículo, sostengo que el aspecto crítico y emancipatorio de la noción hegeliana de libertad, a saber, la libertad social ${ }^{1}$, necesita más investigación y elaboración. El proceso a través del cual los individuos y las comunidades se vuelven libres, es decir, el proceso de actualización de la libertad en general, sólo puede dilucidarse a cabalidad cuando tenemos en cuenta y entendemos la dimensión sensual, somática y afectiva. Quiero sugerir que la libertad humana no es sólo actividad. De manera crucial, la libertad humana implica al mismo tiempo momentos o fases de pasividad. No somos libres simplemente en la medida en que hacemos algo, o en la medida en que estamos en la posición de hacer algo. Nuestra libertad social requiere curiosamente que "sobrellevemos" experiencias particulares, ${ }^{2}$ dirigidas por "fuerzas" que no podemos ni debemos controlar (enteramente).

\footnotetext{
${ }^{1}$ Frederick Neuhouser, Foundations of Hegel's Social Theory. Actualizing Freedom (Cambridge MA: Harvard University Press, 2000); Axel Honneth, Freedom's Right: The Social Foundations of Democratic Life, J. Ganahl trad. (Cambridge UK: Polity Press, 2014). [Hay edición en castellano: El derecho de la libertad. Esbozo de una eticidad democrática (Buenos Aires: Katz ediciones, 2014). NdT.]; "Three, Not Two, Concepts of Liberty: A Proposal to Enlarge Our Moral Self-Understanding", en Hegel on Philosophy in History, R. Zuckert y J. Kreines eds. (Cambridge: Cambridge University Press, 2017).

${ }^{2}$ Esta combinación de actividad y pasividad es lo que caracteriza la noción (hegeliana) de experiencia de Dewey: "Hay (...) un elemento de padecer, de sufrir en su sentido amplio, en cada experiencia". John Dewey, “Art as Experience", en The Later Works of John Dewey: 1925-1953, vol. 10, J. A. Boydston ed. (Carbondale: Southern Illinois University Press, [1934]2008), 47-8. [Hay edición en castellano: El arte como experiencia, J. Claramonte trad. (Barcelona: Editorial Paidós, 2008). NdT] Para una mirada más completa sobre este tema, consultar Arvi Särkelä, Immanente Kritik und soziales Leben. Selbsttransformative Praxis nach Hegel und Dewey (Fráncfort del Meno: Klostermann, 2018).
} 
Mi argumento se desarrolla en tres pasos. Primero, reconstruyo y reformulo la idea de libertad social en el contexto de nociones en disputa. Distingo y hago converger concepciones de libertad negativas y positivas, individuales y colectivas, destacando el carácter procesual y conflictivo de la libertad: en lugar de ser libres como una condición estática o como un punto de llegada, deberíamos considerarnos a nosotros mismos, en nuestros proyectos personales y colectivos, en un esfuerzo de liberación que es constante, en relación y junto con otros. A veces, estas relaciones se vuelven conflictivas. Segundo, después de esbozar las formas en que las recientes contribuciones filosóficas han estado tratando de "naturalizar" la libertad, reviso un argumento que desarrolla Adorno en su Dialéctica Negativa contra la concepción kantiana de la autonomía, y lo aplico también a la noción de libertad social de Hegel. El argumento de Adorno llama nuestra atención sobre los componentes impulsivos o afectivos de la libertad, destacando así lo que puede considerarse su naturaleza negativa. Tercero, me concentro en algunos pasajes de Otro país de James Baldwin de $1962^{3}$ (una novela profundamente en sintonía con la visión de Adorno de la sociedad, la crítica y la transformación) para proporcionar una ejemplificación paradigmática de la libertad social, a saber, el amor apasionado o erótico, que resulta ser particularmente revelador al ilustrar mi revisada noción de libertad social ${ }^{4}$.

\section{Liberarse, volverse libre}

¿Qué es la libertad? Como dice John Dewey, esta "es una palabra aplicada a muchas cosas de variado plumaje y que debe gran parte de su magia a la asociación con una variedad de causas diferentes" ${ }^{\prime 5}$. Tentativamente, uno puede distinguir, primero, entre libertad negativa y

\footnotetext{
${ }^{3}$ James Baldwin, Another Country (Londres: Penguin Books, [1962]1993). [Hay edición en castellano: Otro país, Luis Echavarrí trad. (Barcelona: Versal, 1984). NdT.]

${ }^{4}$ Varias versiones de este documento se han presentado en el taller "Love Matters" (New School for Social Research, Nueva York, febrero de 2019), en la conferencia "Feminismo y teoría crítica" (University of the West of England, Bristol, mayo de 2019), y finalmente en la conferencia "Relevancia contemporánea del naturalismo de Hegel" (Universidad de Parma, junio de 2019). Muchos colegas me han ayudado con valiosas ideas y comentarios, en particular, le debo una cálida gratitud a Borhane Blili-Hamelin, Dagmar Wilhelm, Heikki Ikäheimo, Paul Giladi, Gal Katz, Arvi Särkelä e Italo Testa.

5 John Dewey, "Philosophies of Freedom", en The Later Works of John Dewey: 1925-1953, vol. 3, J. A. Boydston ed. (Carbondale: Southern Illinois University Press, [1928]2008), 92.
} 
positiva ${ }^{6} ;$ y segundo, entre la libertad individual y colectiva. En un movimiento inicial, la libertad negativa individual podría definirse como una actividad sin obstáculos: una persona es libre si tiene la capacidad (poder) y la posibilidad concreta de hacer cualquier cosa que desee hacer, pero también de sentir lo que siente y expresar sus sentimientos de cualquier manera que lo desee. Sin embargo, como bien sabían Hobbes y Freud, tal concepción es ingenua, o incluso peligrosa, ya que se combina con el estado civil, político y social de vivir en común. Se deben introducir ciertas limitaciones a la libertad. Una concepción revisada de la libertad negativa individual, entonces, es actividad y sentimiento libre de coacción: una persona es libre si y sólo si puede llevar adelante acciones y expresar sentimientos sin ser coaccionada o interferida de manera injustificada ${ }^{7}$. Las coacciones justificadas son aquellas que garantizan que las personas se respetan mutuamente con sus acciones y emociones, es decir, que no interfieren con las libertades negativas de los demás y que no ponen en peligro los arreglos institucionales políticos y sociales destinados a proteger con precisión estas libertades. Jean-Paul Sartre propone una versión diferente e interesante de la libertad negativa individual, que enfatiza la actividad a través de la cual cada individuo supera sus propias limitaciones (biología, historia, familia, clase, cultura, geografía, etcétera). Al contrario de Hobbes y Freud, el estado "original" o "natural” no es, en opinión de Sartre, una libertad ilimitada que debe ser limitada para establecer formas sociales y políticas decentes de asociaciones e instituciones. Para Sartre, la "condición natural” es viscosa, vinculante, sofocante, y debe ser continuamente trabajada y trascendida para realizar la vocación más íntima y preciosa del ser humano, su libertad ${ }^{8}$. Simone de Beauvoir ejemplifica en gran medida esta concepción al ilustrar la condición de la mujer ${ }^{9}$. En una línea mucho más hegeliana, ella mejora la perspectiva individualista de Sartre al mostrar cómo las conexiones

\footnotetext{
${ }^{6}$ Ver Isaiah Berlin, "Two Concepts of Liberty”, en Four Essays on Liberty (Oxford: Oxford University Press, 1969). [Hay edición en castellano: "Dos conceptos de libertad", J. Bayón trad., en Cuatro ensayos sobre la libertad (Madrid, Alianza editorial, 1993). NdT.]

${ }^{7}$ Friedrich A. Hayek, The Constitution of Liberty (Londres: Routledge, 1960). [Hay edición en castellano: Los fundamentos de la libertad, J. V. Torrente trad. (Madrid: Unión Editorial, 2008). NdT]

${ }^{8}$ Jean-Paul Sartre, Being and Nothingness. A Phenomenological Essay on Ontology, H.E. Barnes trad. (Nueva York: Washington Square Press, 1984). [Hay edición en castellano: El ser y la nada, J. Valmar trad. (Buenos Aires: Editorial Losada, 2005). NdT]

${ }^{9}$ Simone de Beauvoir, The Second Sex, C. Borde y S. Malovany-Chevallier trads. (Londres: Vintage Books, 2011). [Hay edición en castellano: El segundo sexo, Alicia Martorell trad., Teresa López prol. (Madrid: Editorial Cátedra, 2002). NdT]
} 
intersubjetivas -lazos de solidaridad, confianza, cuidado- son primordiales para empoderar al individuo en su lucha contra las insatisfactorias realidades dadas.

Ahora bien, es crucial entender que la libertad negativa no es prerrogativa de individuos. En la visión neorrepublicana de Philip Pettit, por ejemplo, la libertad se entiende como no-dominación, y es algo que también las colectividades, especialmente las políticas, pueden y deben tener ${ }^{10}$. No estar sujeto a algún poder arbitrario externo o, mejor dicho, ni siquiera ser susceptible a dicho poder ${ }^{11}$, es lo que hace que un "pueblo", los ciudadanos de un estado, sean libres. Sin embargo, la colectivización de la noción de libertad negativa también debe extenderse más allá de los discursos nacionales. Según Pettit, se podría pensar además que el grupo (social) de mujeres es, como grupo, dominado por hombres y que, por lo tanto, no es libre ${ }^{12}$.

Concepciones positivas de la libertad no están demasiado interesadas en una defensa o protección contra agentes externos negativos, o en oponerse a condiciones existentes. Más bien, llaman la atención sobre esos poderes positivos que los seres humanos poseen para conocerse y dominarse a sí mismos, para comprender lo que realmente quieren y sentir, y para determinar sus propias vidas y entornos de acuerdo con sus deseos y proyectos. Esta concepción de la libertad también viene tanto en términos individualistas como colectivistas; además, puede asumir connotaciones morales o ético-políticas. La libertad individual positiva es a menudo considerada en términos de autonomía. En su versión moral, predominantemente kantiana, se refiere a la capacidad de darse a sí mismo las normas que deben recibir nuestra aprobación y ser seguidas. La liberación de las inclinaciones (determinaciones naturales y pasiones) es un requisito previo. Efectivamente, muchos analíticos contemporáneos poskantianos han notado cómo esta noción de autonomía no es una empresa solipsista; implica responsabilidad ante los demás, compromisos compartidos

\footnotetext{
${ }^{10}$ Philip Pettit, "Republican Political Theory", en Political Theory: Tradition and Diversity, A. Vincent ed. (Cambridge: Cambridge University Press, 1997); On the People's Terms. A Republican Theory and Model of Democracy (Cambridge: Cambridge University Press, 2012).

${ }^{11}$ Pettit no identifica su posición como "negativa" en el sentido de Berlin, en la medida que (contra Berlin y otros) toma en consideración la posibilidad, radicada en marcos institucionales y jurídicos, de interferir y no sólo en la interferencia particular. Philip Pettit, "Freedom as Antipower", Ethics 106 (1996): 578.

12 Sobre esto, ver la respuesta de Pettit en "Defending the Robust Demands of the Good", Moral Philosophy and Politics 5 (2018): 115-118, a mi crítica en Federica Gregoratto, "The Robust Demands of Oppression: A Critical View of Pettit's Account of Attachments"”, Moral Philosophy and Politics 5 (2018): 49-68.
} 
intersubjetivamente con respecto a normas y en base a un reconocimiento mutuo como agentes con capacidad moral ${ }^{13}$.

En un sentido no-moral, la libertad positiva puede entenderse como una auténtica autodeterminación ${ }^{14}$. Desde una perspectiva ética, pero también existencial, corresponde a la autorrealización individual, en la que uno llega a ver cuáles son sus verdaderos deseos y aspiraciones, cuáles son los proyectos y, más en general, las formas de vida que son dignas de perseguir y (tratar de) cumplir y realizar. Se puede agregar que la autorrealización requiere también comprender y articular las propias emociones y actuar de acuerdo con tal comprensión $^{15}$. Pero también hay libertad política colectiva: para Hannah Arendt, la libertad colectiva corresponde a una forma de poder ejercida "en concierto" con otros ${ }^{16}$. Tal poder colectivo podría tener consecuencias revolucionarias, crear algo radicalmente nuevo, como por ejemplo, y paradigmáticamente, una nueva constitución y forma política ${ }^{17}$.

La libertad social o hegeliana tiene la ambición de pensar juntos la mayoría de las concepciones antes mencionadas ${ }^{18}$. No aprecia únicamente la independencia individual o política; su foco es más expansivo, abarcando también las relaciones humanas de interdependencias. Es importante destacar que la libertad social es individual y colectiva al mismo tiempo. Porque, por un lado, la autorrealización individual y el florecimiento son posibles gracias a la ayuda, el apoyo y la confirmación proporcionados por otros seres e instituciones humanas; nuestras relaciones de dependencia permiten pues nuestra libertad individual ${ }^{19}$. La autodeterminación política es posible no tanto por la imposición de una

\footnotetext{
${ }^{13}$ Por ejemplo, Robert Brandom, "Freedom and Constraint by Norms", American Philosophical Quarterly 16 (1979): 178-196; Robert Pippin, Hegel's Practical Philosophy: Rational Agency as Ethical Life (Cambridge: Cambridge University Press, 2008); Terry Pinkard, Hegel's Naturalism: Mind, Nature and the Final Ends of Life (Oxford: Oxford University Press, 2012); Paul Giladi, "Hegelian Sittlichkeit, Deweyan Democracy, and Honnethian Relational Institutions: Beyond Kantian Practical Philosophy", en Hegel and Contemporary Practical Philosophy: Beyond Kantian Constructivism, J. Gledhill y S. Stein eds. (Nueva York: Routledge, 2020).

${ }^{14}$ Charles Taylor, "What's Wrong with Negative Liberty?", en Philosophy and the Human Sciences. Philosophical Papers, vol. 2 (Cambridge UK: Cambridge University Press, 1985).

${ }^{15}$ Para una comprensión reciente y persuasiva de la autodeterminación, ver Beate Rössler, Autonomie. Ein Versuch über das gelungene Leben (Berlin: Suhrkamp, 2017), quien -y esto es interesante- presenta su perspectiva como una teoría de la autonomía personal.

${ }^{16}$ Véase, por ejemplo, Hannah Arendt, On Violence (Nueva York: Harcourt Brace Javanovich, 1970), 44. [Hay edición en castellano: Sobre la violencia, C. Criado trad. (Madrid: Alianza Editorial, 2018). NdT.]

${ }^{17}$ Hannah Arendt, On Revolution (Londres: Penguin Books, 2003). [Hay edición en castellano: Sobre la revolución, P. Bravo trad. (Madrid: Alianza Editorial, 2013). NdT.]

${ }^{18}$ Ver Honneth, Freedom's Right.

${ }^{19}$ Ver también: "La libertad es ese poner en libertad y actualización de potencialidades personales que tienen lugar sólo en una asociación rica y variada con otros: el poder de ser un sí mismo individualizado que hace una
} 
voluntad política contra otros actores políticos, sino por la cooperación con otros y como resultado del reconocimiento de otros. Además, podemos realizar nuestra libertad actuando (y sintiendo) junto con otros, como un nosotros, como una colectividad.

La libertad social se actualiza, de acuerdo con una de las últimas definiciones proporcionadas por Axel Honneth, cuando "múltiples sujetos llevan a cabo acciones no forzadas, que se complementan recíprocamente y, por lo tanto, permiten la colaboración libre" ${ }^{20}$. Sin embargo, lo crucial es que este nosotros que actúa libremente no es homogéneo: los propósitos de la acción colectiva se renegocian continuamente valorando la contribución de los diferentes objetivos, hechos y perspectivas que componen el grupo ${ }^{21}$. El individuo que persigue objetivos, acciones y expresa puntos de vista sigue siendo posible sólo gracias a las interacciones con otros, y como parte de la acción comunitaria. La libertad negativa individual se presupone y no desaparece. Como lo sugiere la referencia a la acción "no forzada", la libertad negativa de la colectividad también debe tener su lugar.

Ciertas condiciones estructurales objetivas son primordiales para el desarrollo de la libertad social ${ }^{22}$. En un pasaje conmovedor, Dewey afirma que la posibilidad de libertad es "una con nuestra individualidad, con nuestro ser únicamente lo que nosotros somos y no imitadores y parásitos de otros. Pero como toda otra posibilidad, esta también tiene que ser actualizada; y, como toda otra, sólo se puede actualizar a través de la interacción con condiciones objetivas" ${ }^{23}$. Esto se conecta con la doctrina hegeliana de la Sittlichkeit, el conjunto de prácticas, normas, leyes, hábitos e instituciones que convierten el contexto social habitado por individuos en un contexto social ético:

contribución distintiva y que disfruta a su propio modo de los frutos de la asociación”. John Dewey, "The Public and Its Problems", en The Later Works of John Dewey: 1925-1953, Vol. 2, J. A. Boydston ed. (Carbondale: Southern Illinois University Press, [1927]2008), 329. [Hay edición en castellano: La opinión pública y sus problemas, R. del Castillo trad. E introd. (Madrid: Morata ediciones, 2004). NdT.]

${ }^{20}$ Axel Honneth, "Three, Not Two, Concepts of Liberty", 182.

${ }^{21}$ Téngase en consideración lo que dice Arendt acerca de las condiciones de "pluralidad" y "distinción" en el terreno político, donde tiene lugar el poder. Hannah Arendt, The Human Condition (Chicago: University of Chicago Press, 1998). [Hay edición en castellano: La condición humana, R. Gil Novales trad., Manuel Cruz introd. (Barcelona: Editorial Paidós, 1993). NdT.]

${ }^{22}$ Ver Neuhouser, "Foundations of Hegel's Social Theory", y Giladi, "Hegelian Sittlichkeit".

${ }^{23}$ Dewey, "Philosophies of Freedom", 113-14, cursivas mías. Ver también "Human Nature and Conduct", en The Middle Works of John Dewey: 1899-1924, vol. 14, J. A. Boydston ed. (Carbondale: Southern Illinois University Press, [1922]2008), 210. [Hay edición en castellano: Naturaleza Humana y Conducta, Rafael Castillo trad. (Ciudad de México: Fondo de Cultura Económica, 1964). NdT.] 
El derecho de los individuos a ser determinados subjetivamente como libres se cumple cuando pertenecen a un orden ético actual, porque la certeza de su libertad encuentra su verdad en tal orden objetivo, y es en un orden ético que realmente entran en posesión de su propia esencia o su interna universalidad ${ }^{24}$.

Los individuos pueden darse cuenta de lo que realmente son, de cuál es su determinación interna única (esencia, universalidad interna), sólo si sienten su mundo social como su hogar; si tienen buenas razones para sentirse así; y si el mundo social puede ser verdaderamente considerado como su hogar. La libertad existe no sólo internamente, sino también externamente en las prácticas, normas, leyes, hábitos e instituciones existentes.

Ahora bien, el problema más común que surge al adoptar una perspectiva teórica crítica implicaría invariablemente el siguiente tipo de preguntas: ¿Qué pasa con un contexto social que no puede considerarse como (completamente) racional en un sentido hegeliano? No son libres los individuos que, en tanto agentes sociales en sus respectivos contextos, no pueden identificarse con prácticas racionales, normas, leyes e instituciones, que no se sienten ni deberían sentirse en casa en su propio mundo. Pero ¿pueden ellos, como seres no libres o no completamente libres, luchar para alcanzar la libertad social?

En lo que sigue, situaré aquí el problema teórico crítico, concentrándome en la cuestión de la transformación social y, en particular, en la transformación de condiciones nolibres, más que en la cuestión de los criterios racionales. En otras palabras, no preguntaré cuándo y por qué debemos criticar un contexto social específico por no corresponder a la libertad objetiva, o buscar los criterios en base a los cuales podemos evaluar un contexto social como libertad objetiva habilitante. Más bien, estoy interesada en la cuestión de cómo puede cambiar un contexto social para lograr condiciones objetivas para la libertad. Sostengo que una concepción de la libertad social debe abarcar también los procesos a través de los cuales las prácticas, normas, leyes, hábitos e instituciones no-libres pierden su autoridad y control sobre la vida de las personas. Donde las prácticas, normas, leyes, hábitos e instituciones no-libres se desmantelan y son superadas; donde surgen nuevas prácticas, normas, leyes, hábitos e instituciones, permitiendo un mayor grado de libertad social. Los

\footnotetext{
${ }^{24}$ G. W. F. Hegel, Elements of the Philosophy of Right, A. W. Wood ed., H. B. Nisbet trad. (Cambridge: Cambridge University Press, 1991), §153. [Hay edición en castellano: Principios de la filosofía del derecho o derecho natural y ciencia política, J. L. Vermal trad. (Barcelona: Edhasa, 2005). NdT.]
} 
procesos de liberación o emancipación de las condiciones no-libres y los procesos de creación de los libres pertenecen a la actualización de la libertad social ${ }^{25}$.

Este carácter procesual es transmitido de manera convincente por Dewey, para quien la libertad no es sólo un estado, o simplemente el resultado de un proceso ${ }^{26}$; consiste más bien en "algo que llega a ser, en un cierto tipo de crecimiento; en consecuencias, más que en antecedentes. Somos libres no por lo que somos estáticamente, sino en la medida en que nos estamos volviendo diferentes de lo que hemos sido" ${ }^{27}$. Nótese que, para Dewey, las condiciones objetivas que permiten los procesos de libertad no son ni pueden ser fijados y definidos de una vez para siempre. Parte de las condiciones objetivas que conducen a la libertad es lo que Dewey llama incertidumbre:

[S]i el cambio es genuino, si las cuentas todavía están en proceso de elaboración, y si la incertidumbre objetiva es el estímulo para la reflexión, entonces la variación en la acción, la novedad y el experimento tienen un significado verdadero. (...) Un mundo que está en puntos y momentos lo suficientemente indeterminados como para llamar a la deliberación y dar juego a la elección para dar forma a su futuro es un mundo en el que la voluntad es libre ${ }^{28}$.

Si consideramos la libertad como proceso, también tenemos que dar cuenta de su carácter conflictivo y agonístico. Dewey ${ }^{29}$ describe la problematización y los intentos de revisar las normas, leyes, hábitos e instituciones existentes y no libres como resultado de las luchas entre

\footnotetext{
${ }^{25}$ Christoph Menke también defiende esta tesis. Sin embargo, en su perspectiva el proceso de liberación o emancipación debe permanecer como proceso de liberación de la naturaleza, no un proceso (como intentaré mostrar más adelante) en el cual los aspectos naturales juegan un rol positivo. Ver Menke, "Autonomy and Liberation: The Historicity of Freedom", en Hegel on Philosophy in History, R. Zuckert y J. Kreines eds. (Cambridge UK: Cambridge University Press, 2017).

${ }^{26}$ Esto es lo que parece sugerir Neuhouser: "Siempre se piensa que la libertad es el punto final de algún proceso en que un ser se constituye como lo que es a través de sus relaciones con otro y entonces elimina el carácter extraño de su otro aprehendiéndolo como idéntico a sí (en un sentido que requiere ser todavía precisado), y de esa manera se relaciona sólo consigo mismo", Neuhouser, Foundations of Hegel's Social Theory, 20. Honneth también reconoce el elemento procesual de la libertad social, aunque no con la claridad que lo hace Dewey. Ver Honneth, "Three, Not Two, Concepts of Liberty", 177-78.

${ }^{27}$ Dewey, "Philosophies of Freedom", 108. Mis cursivas.

${ }^{28}$ Dewey, "Human Nature and Conduct", 212-13.

${ }^{29}$ Ver John Dewey, Lectures in China 1919-1920 (Honolulu: Hawaii University Press, 1973); "Lectures in Social and Political Philosophy (China)", editado y con introducción de R. Frega y R. Gronda, European Journal of Pragmatism and American Philosophy 6, no. 2 (2015).
} 
los grupos sociales. En particular, surgen conflictos cuando los grupos subordinados comienzan a exigir el reconocimiento público de sus necesidades, deseos, intereses, identidades y concepciones del bien público ${ }^{30}$. Demandas de este tipo pueden manifestarse, penetrar en la esfera pública y provocar agitación regenerativa, en parte gracias a la acción de los grupos sociales que promueven tales demandas. Sin embargo, también deben existir condiciones objetivas, que pueden considerarse, entre otras cosas, como condiciones de inestabilidad y precariedad [shakiness]: el propósito, el significado y la eficiencia de las normas, leyes, hábitos e instituciones existentes deben haber comenzado a tambalearse, revelando insuficiencias, problemas y defectos. Cuando la libertad ya no es (percibida como) objetivamente garantizada, se modelan márgenes para la acción transformadora.

Al ganar reconocimiento público y, por lo tanto, cambiando (parcialmente) las estructuras y dinámicas dadas de la asociación humana, los grupos subordinados llegan a actualizar su libertad colectiva; al mismo tiempo, toda la asociación se vuelve objetivamente más libre. Desde un punto de vista individual, además, se puede decir que las interrupciones y transformaciones de condiciones no libres dadas surgen cuando los individuos ya no se sienten como en casa en su mundo social; cuando se dan cuenta de que sus emociones, impulsos, deseos corporales y afectos no se respetan, acogen y aprecian adecuadamente a través de las prácticas, normas, leyes, hábitos e instituciones existentes -aunque deberían serlo-. Tal perspectiva subjetiva y emocional no pretende introducir una relación antinómica entre el individuo y la sociedad como eje conflictivo. Por lo tanto, Dewey tiene razón al defender la tesis de que los conflictos y los cambios consiguientes siempre se operacionalizan a nivel grupal ${ }^{31}$. Sin embargo, los sentimientos de alienación emocional ${ }^{32}$ en la sociedad

\footnotetext{
${ }^{30}$ Ver Axel Honneth, The Struggle for Recognition: The Moral Grammar of Social Conflicts, J. Anderson trad. (Cambridge UK: Polity Press, 1995) [Hay edición en castellano: La lucha por el reconocimiento: por una gramática moral de los conflictos sociales, M. Ballestero trad. (Barcelona: Editorial Crítica, 1997). NdT.]; Arvi Särkelä, "Ein Drama in drei Akten. Der Kampf um öffentliche Anerkennung nach Dewey und Hegel”, Deutsche Zeitschrift für Philosophie 61 (2013): 681-696; Federica Gregoratto, "Agonistic Recognition, Intersections and the Ambivalence of Family Bonds: John Dewey's Critical Theory Manifesto in China", Transactions of the Charles S. Pierce Society 53 (2017): 127-145; Justo Serrano, "Articulating a Sense of Powers: An Expressivist Reading of John Dewey's Theory of Social Movements", Transactions of the Charles S. Pierce Society 53 (2017): 53-70.

31 Ver Dewey, Lectures in China, 65.

${ }^{32} \mathrm{El}$ concepto de alienación emocional merecería una explicación en profundidad. Aquí lo uso para indicar una condición doble: primero, la condición de individuos y grupos que son dolorosamente conscientes de que sus emociones individuales y colectivas no se tienen suficientemente en cuenta o no se reconocen a nivel social; segundo, la condición de los individuos y grupos que experimentan sentimientos de incomodidad y aflicción difusos o vagos, que dependen de la falta de reconocimiento público o de invisibilidad, pero no pueden
} 
pueden constituir un poderoso aliciente para reunir colectivos ansiosos por luchar y para participar en acciones grupales.

\section{La naturaleza negativa de la libertad y su carácter afectivo}

Hasta ahora, me he centrado únicamente en condiciones sociales objetivas. Sin embargo, ¿qué pasa con el lugar y el papel de la naturaleza en los debates sobre la libertad? Los teóricos de la libertad negativa y los (neo)republicanos tienden a ignorar la naturaleza y su papel aquí. Por el contrario, Sartre y, más ambiguamente, de Beauvoir consideran que la naturaleza es parte de esas situaciones inmanentes que los ejercicios de libertad se esfuerzan por trascender ${ }^{33}$. Arendt cree que la libertad puede manifestarse únicamente en el ámbito público y político, que debe considerarse programáticamente como independiente de preocupaciones materiales y naturales. Las conceptualizaciones de la libertad positiva en términos de autodeterminación ética y política también ignoran en gran medida las condiciones naturales: al tratar de decidir cuál es la forma de vida que vale la pena vivir, como individuos y/o colectividades, no sería difícil ver cómo es que factores biológicos, neurológicos, químicos, fisiológicos, ambientales, geológicos y otros, podrían desempeñar un papel en la orientación de nuestras preferencias, inclinaciones, gustos, o arreglos materiales. Sin embargo, estos factores no se tienen en cuenta sistemáticamente. En particular en la tradición kantiana, la libertad como autonomía (moral) se logra, por decirlo sin rodeos, fuera del ámbito de la naturaleza. Algunos eruditos de Hegel tienen una actitud similar hacia la libertad. Para citar

articularlos y especificarlos adecuadamente. Tendré que dedicar otro artículo a este concepto; su punto de partida e inspiración se encuentra en Thomas Szanto, "Emotional Self-Alienation", Midwest Studies in Philosophy XLI (2017): 260-286, quien se concentra más específicamente en la autoalienación. Para otra discusión sobre la alienación que puede ser muy útil en este contexto, ver Paul Giladi, "The Agent in Pain: Alienation and Discursive Abuse", International Journal of Philosophical Studies (online), 25 de junio del 2020, consultado en julio de 2020, disponible en https://www.tandfonline.com/doi/ref/10.1080/09672559.2020.1784534?scroll=top.

${ }^{33} \mathrm{Sin}$ embargo, se podría argumentar que para ambos los afectos, emociones y deseos deben ser asumidos y reconocidos a fin de realizar la libertad en sentido propio. Respecto a Sartre, ver Martin Hartmann, "A Comedy We Believe In: A Further Look at Sartre's Theory of Emotions", European Journal of Philosophy 25 (2017): 144-172; Szanto, "Emotional Self-Alienation", 268; respecto a Beauvoir, ver Federica Gregoratto, "The Ambiguity of Love. Beauvoir, Honneth and Arendt on the Relation between Recognition, Power and Violence", Critical Horizons 19 (2018): 18-34. 
el título de un artículo de Pippin de 2002, el carácter procesual del Espíritu, es decir la actualización de la libertad, se desarrolla al "dejar atrás la naturaleza"34.

Recientemente, sin embargo, los teóricos han cuestionado de manera convincente las formas en que los poskantianos han descartado el significado y el papel de la naturaleza para una sociedad libre. Se destacan dos estrategias conceptuales para integrar la naturaleza en la libertad: la primera gira en torno a la noción de hábito, habituación. El núcleo del argumento consiste en enfatizar cómo convertirse en libre requiere la formación de (buenos) hábitos. El hábito se puede definir como una "espiral de primera y segunda naturaleza" ${ }^{35}$, en la que los impulsos naturales se moldean en modalidades recurrentes, efectivas y razonables para interactuar con otros seres humanos en diferentes esferas sociales y con entornos naturales y sociales concebidos en líneas más generales. Al recurrir a la lectura de Dewey de Hegel, la interpretación de Steven Levine es de gran ayuda para aclarar cómo el objetivo de Hegel es "no sólo la libertad articulada por el estado u otras instituciones del Espíritu Objetivo, sino una vida natural libre, una donde la naturaleza ya no se ve como 'externa' o como un 'límite' a nuestra libertad, sino precisamente como la forma 'en la que el espíritu se realiza a sí mismo’. Es en el hábito que el Espíritu se realiza en la naturaleza"36.

La segunda estrategia recupera una noción que hasta ahora no había sido suficientemente apreciada por los estudiosos de Hegel, a saber, la libertad concreta. A la luz de esta noción, y en pocas palabras, la naturaleza se considera como condición de posibilidad para el despliegue de la libertad. Loughlin Gleeson y Heikki Ikäheimo, en particular, utilizan esta idea para criticar la concepción de Pippin de la libertad hegeliana como "autodeterminación racional mediada socialmente"37. Según Pippin, la libertad sería el resultado de la interacción de agentes que se reconocen mutuamente, "cuya cotidiana

\footnotetext{
${ }^{34}$ Robert Pippin, "Leaving Nature Behind: Or Two Cheers for 'Subjectivism'”, en Reading McDowell: On Mind and World, N. Smith ed. (Londres: Routledge, 2002).

${ }^{35}$ Federica Gregoratto y Arvi Särkelä, "Social Reproduction Feminism and Deweyan Habit Ontology", en Habit: Pragmatist Approaches from Cognitive Neurosciences to Social Sciences, F. Caruana e I. Testa eds. (Cambridge UK: Cambridge University Press, 2020).

${ }^{36}$ Steven Levine, "Hegel, Dewey and Habits", British Journal for the History of Philosophy 23 (2015): 651. Sobre el papel central del hábito para la filosofía práctica y el pensamiento social de Hegel, véase también Italo Testa, "The Universal Form of Spirit: Hegel on Habit and Sociality", Hegel-Jahrbuch 1 (2010): 215-220; "Embodied Cognition, Habit, and Natural Agency in Hegel's Anthropology", en The Palgrave Hegel Handbook, M. F. Bykova y K. R. Westphal eds. (Londres: Palgrave, por publicarse); Filippo Ranchio, Dimensionen der zweiten Natur. Hegels praktische Philosophie (Hamburg: Meiner, 2016); Andreja Novakovic, Hegel on Second Nature in Ethical Life (Cambridge UK: Cambridge University Press, 2017).

${ }^{37}$ Pippin, Hegel's Practical Philosophy, 21.
} 
participación reflexiva en el procedimiento de exposición e intercambio de razones representa los medios por los cuales los estándares normativos para las creencias y prácticas colectivas pueden asegurarse dentro de una sociedad particular, históricamente situada" 38 . Uno de los objetivos de la lectura de $\operatorname{Pippin}^{39}$ es purificar la libertad hegeliana de cualquier factor interno-natural (cuerpo, hábitos somáticos, motivaciones de primer orden), estableciendo así una distancia reflexiva respecto de nuestra naturaleza afectiva subjetiva, pero también a fin de lograr una mayor independencia de la naturaleza externa, tanto la primera (las condiciones materiales de nuestra forma de vida) como la segunda naturaleza (las costumbres y hábitos históricamente desarrollados).

Por el contrario, Gleeson sugiere interpretar la libertad hegeliana, para empezar, como estar "en casa" en la naturaleza ${ }^{40}$. La libertad concreta, una instancia de "unidad de unidad y diferencia", equivale entonces a una "reconciliación genuina con esos otros -naturaleza, otras personas y realidad social institucional- de la cual uno depende necesariamente"41. La libertad interna, que es de mayor interés para los argumentos que desarrollo en este artículo, tiene muchas facetas: abarca el yo preintencional, encarnado, o alma (Seele), estados inicialmente no diferenciados como sensaciones, sentimientos y "corporeidad" que posteriormente se ordenan y cultivan por hábitos ${ }^{42}$, pero también varias modalidades de intencionalidad cognitiva y volitiva de orden superior, a saber, el deseo y sus capacidades o pulsiones psicológicamente habilitadoras ${ }^{43}$. De manera crucial, la naturaleza interna también se desarrolla en las relaciones intersubjetivas: estas son relaciones de reconocimiento que no

\footnotetext{
${ }^{38}$ Loughlin Gleeson, "An Evaluative Essentialist and Holistic Reading of Hegelian Concrete Freedom in Outline: Contra Pippin”, Hegel-Jahrbuch 11 (2018): 217.

${ }^{39}$ Ver Pippin, "Leaving Nature Behind"; Hegel's Practical Philosophy, 46-58, 187, 192-94.

${ }^{40}$ G. W. F. Hegel, Philosophy of Mind, W. Wallace y A. V. Miller trads. (Oxford: Clarendon Press, 2007), \$384Z. [Hay edición en castellano: Filosofia del espíritu, E. Barrioberro y Herrán trad. (Madrid: Daniel Jorrro editor, 1907). NdT.]

${ }^{41}$ Ver Gleeson, "An Evaluative Essentialist and Holistic...", 220. Ver también Heikki Ikäheimo, "Holism and Normative Essentialism in Hegel's Social Ontology", en Recognition and Social Ontology, H. Ikäheimo y A. Laitinen eds. (Leiden: Brill, 2011), 161; Loughlin Gleeson y Heikki Ikäheimo, "Hegelian Perfectionism and Freedom", en Perfektionismus der Autonomie, D. Moggach, N. Mooren y M. Quante eds. (Paderborn: Wilhelm Fink Verlag, 2019).

${ }^{42}$ Ver Hegel, Philosophy of Mind, §41Z, 409-410; Italo Testa, "Hegel's Naturalism, or Soul and Body in the Encyclopaedia", en Essays on Hegel's Philosophy of Subjective Spirit, D. Stern ed. (Albany: SUNY Press, 2012).

${ }^{43}$ Ver Hegel, Philosophy of Mind, §41Z, 413-482.
} 
se pueden pensar en términos incorpóreos, puramente normativos, sino que involucran componentes axiológicos y afectivos ${ }^{44}$.

La referencia a la naturaleza interna en Hegel permite desarrollar la dimensión emocional de la libertad que he intentado poner de relieve en la sección anterior, corrigiendo y enriqueciendo así las formas habituales en que se presentan tales relatos. La mayoría de las discusiones sobre la libertad se concentran en los hechos y en la agencia. Cuando se considera a los sentimientos, las pasiones y las emociones en relación con la libertad, se las piensa como opuestos: una persona que se toma su tiempo con sus emociones, o se siente abrumada por ellas, no puede ser libre -esto es algo que se asume comúnmente-. Pero en mi opinión las expresiones y manifestaciones emocionales y corporales, así como la elaboración y articulación de las emociones, se refieren directamente a la libertad. He subrayado que una persona es negativamente libre si y sólo si tiene la capacidad y la posibilidad de sentir lo que siente y expresar sus sentimientos de la manera que desee (dentro de ciertas limitaciones); que la libertad positiva, o la autodeterminación y la autorrealización, requieren también del poder de conocer, dominar, articular y desarrollar adecuadamente las propias emociones ${ }^{45}$. Además, he sugerido que la subordinación de los grupos sociales también consiste en un insuficiente reconocimiento público de sus emociones, en una especie de alienación emocional que se deriva de las normas e instituciones sociales existentes.

Ahora bien, la libertad concreta designa una relación positiva y reconciliada con tales dimensiones emocionales - de hecho, lo contrario de la alienación-. Sin embargo, tal como se presenta, la libertad concreta indica una vez más un punto de llegada, un estado final; está encapsulado en una comprensión estática. Pero ¿y si todavía no somos concretamente libres? ¿Cuál es el papel y la dinámica de la naturaleza en el proceso de liberarse y volverse libre? ${ }^{46}$ A raíz de la crítica de Adorno a la noción de autonomía de Kant, propongo hablar ahora de

\footnotetext{
${ }^{44}$ Ver Gleeson, “An Evaluative Essentialist and Holistic...”, 224.

${ }^{45} \mathrm{Tal}$ relación entre emociones o afectos (y deseos, aspiraciones, impulsos, etc.) y lo que llamo "libertad positiva" ya ha sido tematizada por varios autores de diversas maneras; ver, por ejemplo, Jonathan Lear, Love and Its Place in Nature. A Philosophical Interpretation of Freudian Psychoanalysis (Nueva York: Farrar, Straus \& Giroux, 1990); Harry Frankfurt, The Reasons of Love (Princeton: Princeton University Press, 2004); [Hay edición en castellano: Las razones del amor. El sentido de nuestras vidas, C. Castells trad. (Barcelona: Editorial Paidós, 2004). NdT.]; Beate Rössler, Autonomie. Sin embargo, sus posiciones tienden a dar un rol dominante a las razones y al lado activo de la libertad.

${ }^{46}$ Gleeson e Ikäheimo saben muy bien que rara vez somos concretamente libres; de hecho, consideran que la libertad concreta es el criterio inmanente para evaluar críticamente nuestras sociedades. Como se mencionó anteriormente, sin embargo, no estoy interesada en criterios, sino más bien en los procesos a través de los cuales llegamos a realizar dichos criterios.
} 
la naturaleza de la libertad como un movimiento negativo: la tensión, la ruptura con normas sociales, éticas, políticas establecidas y con patrones de sentimientos y acción.

El objetivo resoluto de Adorno en "Sobre la metacrítica de la razón práctica", parte de la Dialéctica negativa, es revelar la constitución dialéctica de la concepción kantiana de autonomía como autodeterminación moral. En pocas palabras, lo que nos permite ser libres según Kant es, para Adorno, al mismo tiempo lo que nos oprime, lo que nos hace obedientes y complacientes con las normas y los imperativos sociales dados ${ }^{47}$. Actuar libremente corresponde a una forma de acción que debe depender de la identidad del sujeto consigo mismo: el sujeto puede afirmar tal identidad propia cuando actúa de manera que se ajuste a las normas que se ha dado a sí mismo. Como él escribe, "los sujetos son libres, según el modelo kantiano, en la medida en que son conscientes e idénticos a sí mismos; pero no están libres de tal identidad en la medida en que están sujetos a, y perpetuarán, su compulsión" ${ }^{4}$. Además, las acciones de este tipo deben ser autoconscientes: el sujeto debe ser consciente de lo que está haciendo y por qué ${ }^{49}$. Pero ¿qué sucede cuando el sujeto no quiere, o siente que ya no puede, seguir sus propias normas? ¿Qué sucede con las desviaciones más o menos intencionales del modelo de identidad propia? ¿La discrepancia y la no-identidad equivaldrían sin más a la falta de libertad, o podrían abrirse más bien hacia una forma de libertad "mayor"? Una libertad "extendida" podría, por un lado, aceptar e incorporar momentos de desviación, deserciones, suspensiones de la agencia y de la intencionalidad; pero, por el otro, correría también el riesgo de violar la moralidad, faltarle el respeto a otros seres humanos, poniendo en peligro la cooperación pacífica y el potencial para el reconocimiento intersubjetivo y las relaciones de solidaridad ${ }^{50}$.

\footnotetext{
${ }^{47}$ Ver Theodor W. Adorno, Negative Dialectics, E. B. Ashton ed. y trad. (Londres: Continuum, 1981), 232. [Hay edición en castellano: Dialéctica negativa: La jerga de la autenticidad, A. Brotons Muñoz trad. (Madrid: Ediciones Akal, 2014). NdT.] Para una discusión aguda y detallada sobre la paradoja de la noción kantiana de autonomía, que en parte se hace eco de la adorniana sin referirse a ella, ver Thomas Khurana, "Paradoxes of Autonomy. On the Dialectics between Freedom and Normativity", Symposium 17 (2013): 50-74. Sin embargo, Khurana no hace ninguna referencia a la afectividad o la naturaleza.

${ }^{48}$ Adorno, Negative Dialectics, 299.

49 "La experiencia de sí del momento de la libertad depende de la conciencia; el sujeto se sabe libre sólo en la medida en que su acción le resulta idéntica a sí, y tal es el caso sólo de las acciones conscientes", ibíd., 227.

${ }^{50}$ Una dificultad en la argumentación adorniana es que combina normas morales y sociales, políticas y éticas, algo que Kant tiene buenas razones para rechazar. Desafortunadamente, no puedo discutir este punto aquí. En última instancia, no estoy interesada en hablar sobre Kant, o en la plausibilidad de la crítica de Adorno, sino sólo en lo que podemos aprender de Adorno con respecto a la libertad social.
} 
Nótese que la identidad propia requeriría, como se mencionó anteriormente, la separación de la materialidad, el cuerpo, las inclinaciones, por lo tanto, de la naturaleza y las características naturales subjetivas. A los ojos de Adorno, en su lucha por la libertad, una subjetividad incorpórea, abstracta y artificial no puede sino terminar en una especie de jaula de hierro weberiana vuelta hacia adentro, obligándonos a repetir compulsivamente los mismos patrones morales y sociales una y otra vez. Si no se encarna y hace se concreta de esa manera, la libertad de identidad propia se convierte en su opuesto. No obstante, existe la posibilidad de liberarse de una autonomía kantiana no libre, que se encuentra en, y se desencadena (y es movida) por lo que Adorno llama un "addendum”, un momento somático e impulsivo. La aparición y manifestación de este addendum o añadido significa que el sujeto no es y no puede ser, después de todo, idéntico consigo mismo. Un sujeto que intenta ser libre, y que al mismo tiempo trata de no ser preso de su dialéctica, es un sujeto que actúa de manera impredecible, no sabe exactamente qué hacer, se pierde y se abandona a sí mismo:

El impulso, a la vez intramental y somático, conduce más allá de la esfera consciente a la que en todo caso pertenece. Con ese impulso, la libertad se extiende al ámbito de la experiencia; esto anima el concepto de libertad como un estado que no sería más naturaleza ciega de lo que sería naturaleza oprimida ${ }^{51}$.

El addendum no es el otro de razón y agencia; por el contrario, es lo que conecta los dos polos de un dualismo imposible: "es un destello de luz entre los polos de algo que pasó hace mucho tiempo, algo que se volvió casi irreconocible, algo que algún día podría llegar a ser" 52 . El addendum, sin embargo, no simplemente unifica o identifica los dos lados: actividad y pasividad, razón y sinrazón, sensaciones corporales, impulsos y pulsiones por un lado y cognición o deliberación por el otro. Los dos polos permanecen profundamente conectados, pero hay tensión entre ellos, cada uno irreducible al otro. La acción, en particular la praxis emancipadora y transformadora, "necesita algo más, algo físico que la conciencia no agota, algo transmitido a la razón y cualitativamente distinto de ella"53.

¿Es esta crítica de Adorno aplicable también a Hegel? Después de todo, la concepción de libertad de Hegel no consiste en un intercambio de razones puro, incorpóreo e intelectual, y en un establecimiento frío y racional de normas, ni en encontrarnos y realizarnos en un

\footnotetext{
${ }^{51}$ Adorno, Negative Dialectics, 228-229. Mis cursivas.

52 Ibid., 229.

${ }^{53}$ Ibid., 229.
} 
mundo que hemos planteado al hacer y seguir tales razones y normas. Para ser libres, según Hegel, también tenemos que encontrarnos y realizarnos en la naturaleza, en un mundo que no hemos inventado por nosotros mismos. Esto implicaría que la libertad no sólo se trata de respetar deberes, sino también del goce y del bienestar que se pueden encontrar en nuestra vida ética y natural. Además, para ser libres, también debemos haber internalizado ciertos patrones de pensamiento y acción y poder seguirlos en hábitos. Impulsos, afectos, y elementos naturales no deben ser reprimidos o expulsados, sino incorporados: pueden funcionar como motivación para la acción ética, e incluso permitirla.

La idea adorniana del addendum, sin embargo, no se limita a reunir y conciliar normatividad y naturaleza, aunque esto es también lo que hace, como el "fantasma de reconciliación de la naturaleza y la mente" ${ }^{" 54}$. Sin embargo, tal reconciliación sigue siendo fantasmática, siempre amenazada por la posibilidad de ser interrumpida. La tensión, la fricción, o incluso el conflicto entre lo que se da, los impulsos y los afectos que sufrimos, y lo que nosotros, como sujetos libres, resolvemos y decidimos hacer, no puede eliminarse realmente. Los sujetos, como escribe Adorno, "no están libres como naturaleza difusa, no idéntica; y, sin embargo, como esa naturaleza, son libres porque su impulso abrumador -la no identidad del sujeto consigo mismo no es otra cosa- también los librará del carácter coercitivo de la identidad" 55 . Impulsos y afectos, según la lectura adorniana que sugiero, no pueden ser simple y enteramente moldeados en hábitos, incorporados al Geist, acomodados, domesticados $^{56}$. Los impulsos continúan señalando y expresando que el sujeto, incluso el colectivo, es más de lo que es, es y puede ser (y devenir) algo diferente de lo que es: "las bases de la aporía es que la verdad más allá de la identidad obligatoria no sería la franca otredad de esa compulsión; más bien, sería transmitida por la compulsión"

\footnotetext{
${ }^{54}$ Ibídem.

${ }^{55}$ Ibid., 99. Mis cursivas.

${ }^{56}$ Menke también se da cuenta de esto. Para él, sin embargo, el hecho de que haya un resto natural que nunca se puede eliminarse, sigue siendo un problema desde el punto de vista de la libertad; el inevitable conflicto, o paradoja, entre la autonomía y la heteronomía es sólo la expresión de los límites de la autonomía, y no una posibilidad para una expresión más rica de la autonomía. En mi lectura, por el contrario, ciertas experiencias de heteronomía (afectividad, pasividad) podrían contribuir al proceso de actualización de la libertad social. Al final de su ensayo, Menke afirma que "la ruptura con lo social también debe pertenecer a la liberación"; tal ruptura, sin embargo, no tiene nada que ver con la naturaleza. Menke, "Autonomy and Liberation", 173-74, 176.

${ }^{57}$ Adorno, Negative Dialectics, 299. Mis cursivas.
} 
Entiendo que "compulsión” significa estar sujeta a, ser pasiva con respecto a la fuerza que ciertos afectos, impulsos, e imperativos corporales tienen sobre nosotras. En lugar de concebir la pasividad como lo opuesto a la libertad, se considera que la libertad implica esos momentos en los que nos dejamos ir, en que dejamos ir nuestras prácticas y razones habituales, solidificadas e insatisfactorias, nos olvidamos y nos perdemos de maneras que revelan nuestra no-identidad con lo que somos y con las formas en que el contexto social quiere que seamos. El poder o la fuerza de nuestros afectos y deseos puede convertirse en un factor en el proceso de libertad: los momentos somáticos no están ahí para ser moldeados y “domesticados" por las prácticas espirituales, sino también para desafiar y transformar las normas y estructuras que regulan y constituyen las prácticas objetivas de una sociedad determinada.

Los momentos y fases de negatividad, interrupción, disrupción, desafío, y noidentidad pertenecen al proceso de libertad $^{58}$. Estos momentos pueden explicar la naturalidad de la libertad en un sentido de naturaleza deweyano. En Experiencia y naturaleza, la naturaleza es descrita de manera intrigante como "una intersección de espontaneidad y necesidad, de lo regular y lo novedoso, lo terminado y lo inicial" 59 , algo "problemático, por decidir, aún de camino a, hasta ahora inacabado e indeterminado (...). Porque lo inmediatamente dado es siempre lo dudoso; es siempre algo cuyo carácter será asignado y determinado por eventos posteriores. Es un clamor por algo no dado ${ }^{60}$.

Los aspectos afectivos de la libertad podrían albergar no solo el magma indeterminado y desconocido de nuestros impulsos y deseos, sino también "posibilidades ocultas" y "novedades"61. Posibilidades de establecer nuevos hábitos, prácticas e instituciones que han superado la dominación y, por lo tanto, permiten sentirse menos alienados emocionalmente ${ }^{62}$.

\footnotetext{
${ }^{58}$ Dewey también sabe esto; Dewey, "Human Nature and Conduct", 209, 214.

${ }^{59}$ John Dewey, "Experience and Nature", en The Later Works of John Dewey: 1925-1953, vol. 1, J. A. Boydston ed. (Carbondale: Southern Illinois University Press, [1925]2008), 270-71. [Hay edición en castellano: La experiencia y la naturaleza, J. Gaos trad. (Ciudad de México: Fondo de Cultura Económica). NdT.]

${ }^{60}$ Ibid., 262.

${ }^{61}$ Dewey, "Experience and Nature", 28.

${ }^{62}$ Sobre el potencial crítico de esta comprensión de la naturaleza, véase también Federica Gregoratto, "The Critical Nature of Gender: A Deweyan Approach to the Sex/Gender Distinction", Journal of Speculative Philosophy 31, no. 2 (2017): 273-85; también "Capitalism and The Nature of Life-Forms", Critical Horizons (online), 14 de octubre de 2019, consultado en enero de 2020, disponible en https://www.tandfonline.com/doi/abs/10.1080/14409917.2019.1676944?journalCode=ycrh20.
} 


\section{La libertad del amor afectivo}

Sobre la base de los argumentos presentados hasta ahora, podemos decir que la libertad social muestra aspectos somáticos, sensuales y afectivos: nos volvemos libres (también) al dejarnos llevar por dinámicas no-controlables (reacciones químicas, neuronales, fisiológicas) ${ }^{63}$, al escuchar a los placeres y disgustos de los sentidos, al recibir pasivamente la atención, el reconocimiento, el tacto, los impulsos y las inspiraciones de los otros, siendo de esa manera afectados por otros. La naturaleza negativa de tal libertad sensual se reduce al hecho de que tales aspectos naturales a veces pueden intervenir al modo de una interrupción de nuestras formas habituales de estar en el mundo social. Esto debería abrir la posibilidad de cuestionar y transformar normas, hábitos, leyes e instituciones disfuncionales, insatisfactorias, y alienantes, es decir, no-libres. Permítaseme ilustrar esto considerando, en esta sección, experiencias de amor apasionado y erótico.

En los tiempos modernos, este tipo de amor ha sido fuertemente asociado con la libertad. La libertad negativa individual es, por ejemplo, la forma paradigmática en la que se practica el amor sexual en las condiciones actuales de la sociedad neoliberal: según el sombrío diagnóstico de Eva Illouz en 2019, en los así llamados mercados románticos, los actores sociales buscan hoy en día predominantemente libertades hedónicas. Persiguen los placeres sexuales y emocionales individuales sin tolerar limitaciones o restricciones de ningún tipo, incluyendo aquellas que se asocian necesariamente en compromisos amorosos a largo plazo ${ }^{64}$. En un sentido mucho más positivo, Stanley Cavell muestra, por el contrario, que las relaciones de amor (y amistad) que resultan exitosas son primordiales en los procesos individuales de autocomprensión, autodeterminación y autorrealización ${ }^{65}$. Las parejas

\footnotetext{
63 También podemos intervenir en estos aspectos de nuestros cuerpos, podemos controlar y dirigir nuestras reacciones químicas, neuronales y fisiológicas, hoy más que ayer, gracias, por ejemplo, a las tecnologías de mejoramiento neurológico. Algunos argumentan que, precisamente cuando están involucradas emociones fuertes, dicha intervención aumenta nuestra libertad. Ver Brian D. Earp y Julian Savulescu, Love Drugs. The Chemical Future of Relationships (Stanford: Stanford University Press, 2020). No estoy completamente en contra de esta línea de argumentación; sin embargo, en este artículo mi argumento es que el proceso de libertad también incluye la adopción de dinámicas no-controlables.

${ }^{64}$ Eva Illouz, The End of Love: A Sociology of Negative Relations (Oxford: Oxford University Press, 2019).

${ }^{65}$ Ver Stanley Cavell, The Pursuit of Happiness. The Hollywood Comedy of Remarriage (Cambridge MA: Harvard University Press, 1981). [Hay edición en castellano: La búsqueda de la felicidad: La comedia de enredo matrimonial en Hollywood, E. Iriarte Goñi trad. (Barcelona: Editorial Paidós, 1999). NdT.]
} 
románticas (que también son amigos) se ayudan mutuamente a entender cuál es la verdadera naturaleza de sus deseos, de lo que quieren ser (y llegar a ser) y lo que imaginan como una vida que vale la pena vivir, a nivel individual, ético y político. Paul Kottman también identifica la libertad en el amor como la capacidad, compartida y construida intersubjetivamente, de dar sentido a un mundo misterioso y amenazante ${ }^{66}$.

El amor, incluido el amor erótico y apasionado, aparece entonces de la manera más paradigmática en la explicación de la libertad social. Como algunos han argumentado, la fórmula típica que ilustra la libertad hegeliana, "ser-con-uno-mismo-en-otro", aparece como una posibilidad real, no-ideal y no-ideológica, especialmente cuando se consideran las interacciones entre personas que forman grupos sociales (muy) restringidos e íntimos ${ }^{67}$. Si uno toma en cuenta las relaciones entre extraños, colegas de trabajo, ciudadanos o seres humanos en general, la sospecha de que la libertad social sigue siendo un mero ideal y de que, por lo tanto, corre el riesgo de reforzar las construcciones ideológicas, parece bastante justificada ${ }^{68}$. Ciertamente, uno podría disputar el lugar especial atribuido al amor y mostrar cómo su libertad no puede sino equivaler también a la idealidad y la ideología. Para los fines de este capítulo, el punto que quiero defender es que el amor y las relaciones sexuales pueden representar un pertinente "laboratorio social" en el cual, a pequeña escala, podemos aprender algo sobre la libertad en general.

Las referencias de Hegel al amor romántico que une a la mujer y al hombre en el contexto ético de la familia representan un ejemplo paradigmático de cómo se desarrolla la libertad social al incorporar, moldear y ordenar ( ¡o incluso disciplinar!) impulsos y sentimientos. El amor sexual (pero también el amor familiar entre padres e hijos) es un apego inmediato, porque tiene su origen no en el pensamiento, que es mediado o reflexivo, sino en el "sentimiento natural" " 99 . Como aclara Neuhouser, la familia califica como racional porque "al institucionalizar el amor sexual monógamo, permite a sus miembros adultos expresar uno de los impulsos humanos más fuertes de una manera que sea consistente con la actualización de la libertad"70. Los impulsos y las necesidades naturales no sólo son compatibles con la

\footnotetext{
${ }^{66}$ Paul Kottman, Love as Human Freedom (Stanford: Stanford University Press, 2017).

${ }^{67}$ Ver Neuhouser, Foundations of Hegel's Social Theory, 20.

${ }^{68}$ Ver Karen Ng, "Social Freedom as Ideology”, Philosophy \& Social Criticism 45 (2018): 795-818.

${ }^{69}$ Hegel, Elements of the Philosophy of Right, §158. Cf. Neuhouser, Foundations of Hegel's Social Theory, 135.

${ }^{70}$ Neuhouser, Foundations of Hegel's Social Theory, 169.
} 
libertad, sino que contribuyen positivamente a su realización: los impulsos sexuales son aquellas fuerzas que unen a dos adultos en relaciones amorosas y ayudan a mantenerlos unidos. Dentro de un parentesco de este tipo, "los imperativos de la naturaleza están en una armonía más completa con los del espíritu; las demandas naturales y éticas están unidas, cada una reforzando a la otra"71. Aquí hay una "unidad interpenetrante" de la naturaleza y la libertad.

Las pulsiones e impulsos, como escribe Alison Stone, “deben cultivarse para alcanzar un acuerdo espontáneo [concur from within] con los requisitos racionales que la voluntad se 'resuelve' a obedecer"'72. El marco ético del matrimonio (por ejemplo) no sofoca las pulsiones, impulsos sexuales, o mejor dicho, sentimientos sexuales, sino que permite extraer y reforzar el elemento proto-racional de respeto y compromiso mutuo que le son inherentes ${ }^{73}$. Los "aspectos transitorios, volubles y puramente subjetivos del amor"74, cuando se anclan al marco institucional de la familia burguesa, convierten su "determinación natural inmediata" en una "esencia sustancial"75.

Sin embargo, está claro cómo la naturaleza ética (es decir, la libertad) del amor, tal como se expresa y se hace posible en el matrimonio y a través de él, se destaca sólo cuando es posible una reconciliación con la naturaleza. Esto significa que la dimensión natural de las pulsiones, impulsos y afectos debe ser "transfigurada", "superada":

el matrimonio contiene un momento natural (...) [En él] la relación natural se transfigura en espiritual sin ser dejada de lado (...) El momento ético consiste en la superación de la naturaleza. Por otro lado, esta relación natural no debe considerarse como algo degradante o incorrecto, o como un defecto al que uno está sujeto simplemente como resultado de la imperfección de la Naturaleza humana ${ }^{76}$.

La conocida formulación de la libertad como "ser-con-uno-mismo-en-un-otro" designa una reconciliación entre uno mismo y otro: el que un ente esté "consigo mismo" y, por lo tanto, se autodetermine, ocurre en su estar necesariamente en relación con otro. La reconciliación

\footnotetext{
${ }^{71}$ Ibidem.

72 Alison Stone, Petrified Intelligence: Nature in Hegel's Philosophy (Nueva York: SUNY Press, 2005$), 114$.

${ }^{73}$ Ver Hegel, Elements of the Philosophy of Right, §161. Comparar Stone, Petrified Intelligence, 115.

${ }^{74}$ Hegel, Elements of the Philosophy of Right, $\$ 161 \mathrm{~A}$.

${ }^{75}$ Ibid., $\$ 19$.

${ }^{76}$ G. W. F. Hegel, Philosophie des Rechts: Die Vorlesung von 1819/20 in einer Nachschrift, D. Henrich ed. (Fráncfort del Meno: Suhrkamp. 1983), 130-31.
} 
funciona cuando el otro se subordina, pero no en un gesto de expulsión o destitución, sino uno de incorporación: la libertad se actualiza no separándose del otro sino incorporándolo ${ }^{77}$. Sin embargo, a partir de Adorno, hemos visto cómo el momento somático no puede ser (siempre) incorporado. Adorno no excluye el que los impulsos insurgentes puedan eventualmente ser aceptados, cultivados, y hacerse parte integral de nuestra vida ética. El sentido de su argumento consiste, creo, en una invitación a desviar nuestra mirada del estado final, del momento de la reunión, y concentrarnos más bien en las fases de fricción, tensión y conflicto entre el (supuesto) orden ético y los afectos que se resisten a la asimilación. Porque es en estos momentos que pueden surgir espacios para la crítica y la transformación.

Permítaseme ilustrar esto desplegando algunas de las figuras narrativas que pueblan la novela Otro país (1962) de James Baldwin. Una manera perfectamente razonable de entender la novela es como una crítica de las normas y estructuras capitalistas, sexistas y racistas que constituyeron el Estados Unidos de las décadas de 1950 y 1960, - la misma sociedad, por cierto, que provocó los diagnósticos críticos más negativos de Adorno ${ }^{78}$. El "otro país" del título podría tomarse para referir a un mundo alternativo, (im)posible, utópico, en el que sus habitantes podrían finalmente realizarse a sí mismos y sus deseos -expresarse a través de su arte sin tener que subyugarlo a la necesidad de lucro, encontrar una conexión real, cariñosa, atenta y comprensiva entre ellos más allá de las diferencias raciales y de clase, siendo respetados y reconocidos como personas no sólo a pesar de ellos, sino precisamente en virtud de su ser "auténtico" (sexual, racial).

En pocas palabras, "otro país" es el país en el que se realiza la libertad social. Sin embargo, de manera adorniana, este país no debe ser visto ni experimentado como algo positivo, sino sólo inferido de "configuraciones" de las relaciones interpersonales que han sido dañadas, en las que Baldwin traza lo que Adorno llama "la ambigüedad de la melancolía"79. La idea de "otro país" puede considerarse, en la terminología adorniana, como

\footnotetext{
${ }^{77}$ Neuhouser, Foundations of Hegel's Social Theory, 19.

${ }^{78}$ En lo que sigue, no quiero sugerir de ninguna manera que el trabajo y la visión de Baldwin puedan reducirse al marco adorniano. Para los propósitos de este artículo, sin embargo, una lectura conjunta de los dos autores puede ser útil. Para más información sobre el pensamiento de Baldwin, especialmente a la luz de la teoría social crítica actual, ver Eddie Glaude Jr., Begin Again: James Baldwin's America and Its Urgent Lessons (Nueva York: Random House, 2020).

79 Theodor W. Adorno, Minima Moralia: Reflections on a Damaged Life, E. F. N. Jephcott trad. (Londres: Verso, [1951]2005), §78, 121. [Hay edición en castellano: Minima moralia: reflexiones desde la vida dañada, Obra completa 4, Joaquín Chamorro trad. (Madrid: Editorial Akal, 2013). NdT]
} 
una figura "de lo irreal" $" 80$ que puede servir como el "punto de vista de la redención" 81 . Sin embargo, hacia el final de la novela, se arroja una luz sobre este mundo, sobre este país, "por la redención" misma: este es el momento en que dos protagonistas masculinos, Eric y Vivaldo, descubren su atracción sexual mutua y sus mutuas emociones amorosas. En este momento se vislumbra un mundo mejor, y tenemos la esperanza de que se pueden desarrollar y cultivar capacidades cognitivas y prácticas para la comprensión crítica y la transformación.

En la novela, Baldwin presenta los males sociales -la vida dañada, en términos adornianos- que es el foco de su crítica, en forma de daños de las relaciones amorosas, tanto en el amor sexual como en la amistad. El principal problema que detecta es la impenetrabilidad de los individuos, la trampa de su subjetividad encerrada que no les permite ver y percibir el mundo desde la perspectiva de otros seres humanos. Esto es particularmente difícil, si no imposible, para los hombres o mujeres blancos que entablan relaciones con hombres o mujeres negros, y viceversa. Además, el estigma y el miedo a la homosexualidad impiden que muchos hombres profundicen su amistad con otros hombres ${ }^{82}$. Las normas que regulan la raza y la sexualidad se cruzan, en la novela, de manera que dañan las relaciones amorosas y las relaciones sociales en general.

¿Pueden cambiar esas normas? Y si pueden cambiar, ¿cómo exactamente? La única respuesta positiva (provisional y parcial) a esta pregunta es compartida por Vivaldo, un joven italoamericano aspirante a escritor, de orígenes humildes, que lleva una vida bohemia en el West Village de Nueva York. En la primera parte de la novela, lo vemos luchando, sin éxito, por comunicarse con su mejor amigo Rufus, el saxofonista de Black Jazz. Rufus está pasando por tiempos difíciles, incapaz de sobrellevar el racismo que lo rodea. Está en relaciones con una mujer blanca, a quien ama, pero a quien no puede tratar con el cuidado y el respeto que sabe que se merece. Eventualmente se suicida. Como es de esperar, Vivaldo está desgarrado por un fuerte sentimiento de culpa y desesperación por no haber encontrado las palabras ni los gestos para comunicar verdaderamente a Rufus su amor y su amistad. Su genuino esfuerzo por demostrarle a él, y a todos los demás, que una nueva configuración de las relaciones interraciales es una posibilidad real, había fallado. En las siguientes secciones del libro, Vivaldo se enamora de Ida, la hermana de Rufus. Entonces se le presenta otra oportunidad.

\footnotetext{
${ }^{80}$ Ibid., $\$ 78,122$.

${ }^{81}$ Ibid., §153, 247.

${ }^{82}$ Relaciones sexuales entre mujeres no son consideradas.
} 
Dolorosamente, a pesar de su profunda atracción y admiración por ella, parece incapaz, nuevamente, de escucharla y comprenderla verdaderamente, de abrazarla, de ayudarla de una manera que realmente es importante para ella.

Las cosas comienzan (o podrían comenzar) a cambiar en el momento que Vivaldo se deja atraer con una inesperada pasión por su amigo Eric, un antiguo amante de Rufus. La escena del acto sexual es narrativamente bastante compleja ${ }^{83}$ : comienza con un sueño, en el que Vivaldo experimenta dolor y angustia mortal, pero finalmente se conecta sexualmente con Rufus. Despertando lentamente del sueño, siente su deseo por Eric y el deseo de Eric por él -como si su sueño con Rufus tuviera el efecto de acercarlo a Eric. Al mismo tiempo, compartir la cama de Eric, en la que accidentalmente había terminado durmiendo su borrachera de la noche anterior, lo acerca a Rufus de una manera que no había sido posible en la vida real. Las primeras etapas de su encuentro suceden en un estado semiconsciente, al menos para Vivaldo, quien simplemente se rinde ante los nuevos sentimientos de abandono, “entregado al lujo, al ardiente sopor de la pasividad" ${ }^{84}$ Vivaldo está abandonando algo de su viejo sí mismo habitual: sobre todo, los rasgos de carácter que son típicos de una identidad masculina tradicional, como la necesidad de estar constantemente activo y en control ${ }^{85}$. Se dejó guiar, poseer, ser objeto de la acción de otro, y no sólo de manera sexual. Téngase en cuenta que la experiencia no es simplemente de alegría y placer. Una cadena de ansiedades y preocupaciones cruzan la mente y el cuerpo de Vivaldo, no está seguro de si el sueño con Rufus se ha convertido en una pesadilla ${ }^{86}$. Sin embargo, las dudas reactivan su conciencia y lo hacen alcanzar un nuevo tipo de autoconciencia:

El sueño vaciló al borde de la pesadilla: ¿cuántos años tenía este rito, este acto de amor, cuán profundo? ¿En el tiempo impersonal, en los actores? Sintió que había saltado un precipicio hacia un aire que lo sostenía inexorablemente, como el salado mar sostiene al nadador: y parecía ver, enorme y horriblemente abajo, en el fondo de su corazón, el corazón que

\footnotetext{
${ }^{83}$ Ver Baldwin, Another Country, 381ss.

${ }^{84}$ Ibid., 385. Mis cursivas.

${ }^{85}$ Ver Brandon Gordon, "Physical Sympathy: Hip and Sentimentalism in James Baldwin's Another Country", MFS Modern Fiction Studies 57 (2011): 75-95.

${ }^{86}$ Baldwin, Another Country, 386.
} 
contenía todas las posibilidades que podía nombrar y otras que no podía nombrar ${ }^{87}$.

Entre las posibilidades que podrían nombrarse se encuentra, algunas páginas más tarde, una reunión con su novia negra. Por primera vez, justo después de su encuentro sexual con Eric, Vivaldo logra tener una conversación profunda y honesta con Ida, que finalmente parece permitir un compartir genuino. Este es el tipo de compartir que es posible, siguiendo a Audré Lorde, en actos de auténtico amor erótico: “compartir la alegría, ya sea física, emocional, psíquica o intelectual, forma un puente entre los participantes que puede ser la base para comprender mucho de lo que no se comparte entre ellos, y disminuye la amenaza de su diferencia" $" 88$.

Es interesante que en esta escena el compartir que ocurre inesperadamente entre Vivaldo y Eric es lo que conduce al cambio en la comunicación entre Vivaldo y otro personaje, Ida. Como si la experiencia de rendirse finalmente al extraño deseo, una experiencia de alegría y miedo simultáneos, disolución en la otredad y volver a uno mismo, hubiera despertado en Vivaldo una mayor sensibilidad y la capacidad cognitiva y emocional para tomar el punto de vista del otro. Como si la pasión experimentada por los dos hombres no pudiera estar sólo en la habitación de Eric, sino que también tuviera que propagarse a otras habitaciones, afectando positivamente otras relaciones, liberando potenciales para una comprensión más profunda, compartiendo y amando más en general ${ }^{89}$.

Nótese cómo las diferentes concepciones de libertad que están en juego aquí convergen elegantemente dentro de la noción global de libertad social. Para empezar, Vivaldo ejerce su libertad individual: persigue -aunque no consciente ni activamente- sus impulsos puramente individuales, los que en una primera fase son indeterminados y confusos (por ejemplo, no se identificó como homosexual, ni entendía enteramente la naturaleza de su deseo). Téngase en cuenta que es mientras se deja llevar por tales afectos que comienza a comprender lo que quiere, tanto con Eric como también con Ida. Todavía no ha logrado la

\footnotetext{
${ }^{87}$ Ibídem.

${ }^{88}$ Audre Lorde, "The Uses of the Erotic: The Erotic as Power", en Sister Outsider: Essays and Speeches (Berkeley: Crossing Press, 2007), 56. [Hay edición en castellano: La hermana, la extranjera: artículos y conferencias, M. Corniero Fernández trad. (Madrid: horas y Horas, 2003). NdT.]

${ }^{89}$ Unos años antes, Baldwin había descrito un movimiento opuesto en su famosa novela Giovanni's Room (1956): la incapacidad de David de amar a Giovanni, el confinamiento de sus sentimientos (de culpabilidad) dentro de las paredes estrechas y sofocantes de su habitación, resultó en la erosión y finalmente destrucción violenta de su relación con su prometida Hella también.
} 
autodeterminación, pero la dirección es prometedora. Además, la escena sexual entre Vivaldo y Eric es una buena ilustración de lo que significa experimentar la libertad juntos, como un (minúsculo) nosotros. En la unión sexual, que es un enredo de actividad y pasividad, surgen nuevas posibilidades para ambos -y para otros-. Finalmente, sus pasiones-acciones hacen un gesto hacia nuevas posibilidades para la sociedad en general, se abren a la imaginación de otro país.

El final de la novela no es necesariamente optimista, pero al menos permanece abierto: ¿Es Vivaldo, en tanto hombre blanco, finalmente capaz de comprender el sufrimiento de los negros? ¿Es Ida finalmente capaz de dejar ir su odio para permitir que la vean y la traten según nuevos patrones? ¿Es el reconocimiento entre ellos ahora una posibilidad real? Sin dar una respuesta clara, la novela muestra cómo este tipo de reconocimiento, necesario en el paradigma hegeliano para el despliegue de la libertad social, presupone y requiere liberación. En este caso, liberación de identidades raciales (y sexuales) opresivas y alienantes, de estructuras sociales que ordenan y organizan las relaciones interpersonales en formas que reproducen, si es que no refuerzan, la dominación, así como los patrones de relaciones monógamas y heterosexuales. Por cierto, la liberación depende a veces de las prácticas de dar y ofrecer razones. Pero a veces también puede ser el resultado de experiencias de noidentidad, en las que estamos alejados de nosotros mismos, en las que nos damos cuenta de que podemos ser, y tal vez ya somos, diferentes de lo que hemos sido, como individuos y como comunidades.

\section{Agradecimientos}

Una versión modificada de este artículo será publicada en Paul Giladi editor, Hegel and the Frankfurt School: Traditions in Dialogue (Londres: Routledge, 2020). Traducción desde el inglés por Benjamín Varas Arnello. 


\section{Referencias bibliográficas}

Adorno, Theodor W. Minima Moralia: Reflections on a Damaged Life. E. F. N. Jephcott traductor. Londres: Verso, [1951]2005.

Negative Dialectics, E. B. Ashton editor y traductor. Londres: Continuum, 1981.

Arendt, Hannah. On Revolution. Londres: Penguin Books, 2003.

. The Human Condition. Chicago: University of Chicago Press, 1998.

On Violence. Nueva York: Harcourt Brace Javanovich, 1970.

Baldwin, James. Another Country. Londres: Penguin Books, [1962]1993.

Beauvoir, Simone de. The Second Sex. Constance Borde y Sheila Malovany-Chevallier traductoras. Londres: Vintage Books, 2011.

Berlin, Isaiah. "Two Concepts of Liberty". En Four Essays on Liberty. Oxford: Oxford University Press, 1969.

Brandom, Robert. "Freedom and Constraint by Norms". American Philosophical Quarterly 16 (1979): 178-196.

Cavell, Stanley. The Pursuit of Happiness. The Hollywood Comedy of Remarriage. Cambridge MA: Harvard University Press, 1981.

Dewey, John. "Lectures in Social and Political Philosophy (China)", editado y con introducción de Roberto Frega y Roberto Gronda. European Journal of Pragmatism and American Philosophy 6, no. 2 (2015).

Lectures in China 1919-1920. Honolulu: Hawaii University Press, 1973.

“Art as Experience”. En The Later Works of John Dewey: 1925-1953, vol. 10. Jo

Ann Boydston editora. Carbondale: Southern Illinois University Press, [1934]2008).

. "Philosophies of Freedom". En The Later Works of John Dewey: 1925-1953, vol. 3.

Jo Ann Boydston editora. Carbondale: Southern Illinois University Press, [1928]2008.

. "The Public and Its Problems". En The Later Works of John Dewey: 1925-1953,

Vol. 2, Jo Ann Boydston editora. Carbondale: Southern Illinois University Press, [1927]2008.

"Experience and Nature". En The Later Works of John Dewey: 1925-1953, vol. 1,

Jo Ann Boydston editora. Carbondale: Southern Illinois University Press, [1925]2008. 
"Human Nature and Conduct". En The Middle Works of John Dewey: 1899-1924, vol. 14, Jo Ann Boydston editora. Carbondale: Southern Illinois University Press, [1922]2008.

Earp, Brian D. y Julian Savulescu. Love Drugs. The Chemical Future of Relationships. Stanford: Stanford University Press, 2020.

Frankfurt, Harry. The Reasons of Love. Princeton: Princeton University Press, 2004.

Giladi, Paul. "Hegelian Sittlichkeit, Deweyan Democracy, and Honnethian Relational Institutions: Beyond Kantian Practical Philosophy". En Hegel and Contemporary Practical Philosophy: Beyond Kantian Constructivism. James Gledhill y Sebastian Stein editors. Nueva York: Routledge, 2020.

. "The Agent in Pain: Alienation and Discursive Abuse". International Journal of Philosophical Studies (online). 25 de junio del 2020. Consultado en julio de 2020, disponible en https://www.tandfonline.com/doi/ref/10.1080/09672559.2020.1784534?scroll=top.

Glaude, Eddie Jr. Begin Again: James Baldwin's America and Its Urgent Lessons. Nueva York: Random House, 2020.

Gleeson, Loughlin. “An Evaluative Essentialist and Holistic Reading of Hegelian Concrete Freedom in Outline: Contra Pippin”. Hegel-Jahrbuch 11 (2018): 217.

Gleeson, Loughlin y Heikki Ikäheimo. "Hegelian Perfectionism and Freedom". En Perfektionismus der Autonomie. Douglas Moggach, Nadine Mooren y Michael Quante editors. Paderborn: Wilhelm Fink Verlag, 2019.

Gordon, Brandon. 'Physical Sympathy: Hip and Sentimentalism in James Baldwin's Another Country”. MFS Modern Fiction Studies 57 (2011): 75-95.

Gregoratto, Federica. "Capitalism and The Nature of Life-Forms". Critical Horizons (online). 14 de octubre de 2019. Consultado en enero de 2020, disponible en https:/www.tandfonline.com/doi/abs/10.1080/14409917.2019.1676944?journalCode=y $\operatorname{crh} 20$.

. "The Ambiguity of Love. Beauvoir, Honneth and Arendt on the Relation between Recognition, Power and Violence". Critical Horizons 19 (2018): 18-34.

. "The Robust Demands of Oppression: A Critical View of Pettit's Account of Attachments"”. Moral Philosophy and Politics 5 (2018): 49-68. 
. "Agonistic Recognition, Intersections and the Ambivalence of Family Bonds: John

Dewey's Critical Theory Manifesto in China". Transactions of the Charles S. Pierce Society 53 (2017): 127-145.

- "The Critical Nature of Gender: A Deweyan Approach to the Sex/Gender Distinction". Journal of Speculative Philosophy 31, no. 2 (2017): 273-285.

Gregoratto, Federica y Arvi Särkelä. "Social Reproduction Feminism and Deweyan Habit

Ontology”. En Habit: Pragmatist Approaches from Cognitive Neurosciences to Social

Sciences, Fausto Caruana e Italo Testa editors. Cambridge: Cambridge University Press, 2020.

Hartmann, Martin. "A Comedy We Believe In: A Further Look at Sartre's Theory of Emotions". European Journal of Philosophy 25 (2017): 144-172.

Hayek, Friedrich A. The Constitution of Liberty. Londres: Routledge, 1960.

Hegel, G. W. F. Philosophy of Mind, William Wallace y Arnold V. Miller traductores. Oxford: Clarendon Press, 2007. Elements of the Philosophy of Right. Allen W. Wood editor, Hugh B. Nisbet traductor. Cambridge: Cambridge University Press, 1991. . Philosophie des Rechts: Die Vorlesung von 1819/20 in einer Nachschrift. Dieter Henrich editor. Fráncfort del Meno: Suhrkamp. 1983.

Honneth, Axel. "Three, Not Two, Concepts of Liberty: A Proposal to Enlarge Our Moral Self-Understanding". En Hegel on Philosophy in History. Rachel Zuckert y James Kreines editores. Cambridge UK: Cambridge University Press, 2017.

Freedom's Right: The Social Foundations of Democratic Life. Joseph Ganahl traductor. Cambridge UK: Polity Press, 2014. The Struggle for Recognition: The Moral Grammar of Social Conflicts. Joel Anderson traductor. Cambridge UK: Polity Press, 1995.

Illouz, Eva. The End of Love: A Sociology of Negative Relations. Oxford: Oxford University Press, 2019.

Ikäheimo, Heikki. "Holism and Normative Essentialism in Hegel's Social Ontology”. En Recognition and Social Ontology, Heikki Ikäheimo y Arto Laitinen editors. Leiden: Brill, 2011. 
Khurana, Thomas. "Paradoxes of Autonomy. On the Dialectics between Freedom and Normativity”. Symposium 17 (2013): 50-74.

Kottman, Paul. Love as Human Freedom. Stanford: Stanford University Press, 2017.

Lear, Jonathan. Love and Its Place in Nature. A Philosophical Interpretation of Freudian Psychoanalysis. Nueva York: Farrar, Straus \& Giroux, 1990.

Levine, Steven. "Hegel, Dewey and Habits". British Journal for the History of Philosophy 23 (2015).

Lorde, Audre. "The Uses of the Erotic: The Erotic as Power". En Sister Outsider: Essays and Speeches. Berkeley: Crossing Press, 2007.

Menke Christoph. “Autonomy and Liberation: The Historicity of Freedom”. En Hegel on Philosophy in History. Rachel Zuckert y James Kreines editores. Cambridge: Cambridge University Press, 2017.

Neuhouser, Frederick. Foundations of Hegel's Social Theory. Actualizing Freedom. Cambridge MA: Harvard University Press, 2000.

Ng, Karen. "Social Freedom as Ideology". Philosophy \& Social Criticism 45 (2018): 795818.

Novakovic, Andreja. Hegel on Second Nature in Ethical Life. Cambridge: Cambridge University Press, 2017.

Pettit, Philip. "Defending the Robust Demands of the Good". Moral Philosophy and Politics 5 (2018): 115-118.

On the People's Terms. A Republican Theory and Model of Democracy. Cambridge: Cambridge University Press, 2012.

. "Republican Political Theory". En Political Theory: Tradition and Diversity. Andrew Vincent editor. Cambridge: Cambridge University Press, 1997.

“Freedom as Antipower". Ethics 106 (1996).

Pinkard, Terry. Hegel's Naturalism: Mind, Nature and the Final Ends of Life. Oxford: Oxford University Press, 2012.

Pippin, Robert. Hegel's Practical Philosophy: Rational Agency as Ethical Life. Cambridge: Cambridge University Press, 2008.

“Leaving Nature Behind: Or Two Cheers for 'Subjectivism'”. En Reading McDowell: On Mind and World, Nicholas Smith editor. Londres: Routledge, 2002. 
Ranchio, Filippo. Dimensionen der zweiten Natur. Hegels praktische Philosophie. Hamburg: Meiner, 2016.

Rössler, Beate. Autonomie. Ein Versuch über das gelungene Leben. Berlin: Suhrkamp, 2017.

Särkelä, Arvi. Immanente Kritik und soziales Leben. Selbsttransformative Praxis nach Hegel und Dewey. Fráncfort del Meno: Klostermann, 2018.

. "Ein Drama in drei Akten. Der Kampf um öffentliche Anerkennung nach Dewey und Hegel". Deutsche Zeitschrift für Philosophie 61 (2013): 681-696.

Sartre, Jean-Paul. Being and Nothingness. A Phenomenological Essay on Ontology. Hazel E. Barnes traductor. Nueva York: Washington Square Press, 1984.

Serrano, Justo. "Articulating a Sense of Powers: An Expressivist Reading of John Dewey's Theory of Social Movements". Transactions of the Charles S. Pierce Society 53 (2017): 53-70.

Stone, Alison. Petrified Intelligence: Nature in Hegel's Philosophy. Nueva York: SUNY Press, 2005.

Szanto, Thomas. "Emotional Self-Alienation”. Midwest Studies in Philosophy XLI (2017): 260-286.

Taylor, Charles. "What's Wrong with Negative Liberty?". En Philosophy and the Human Sciences. Philosophical Papers, vol. 2. Cambridge: Cambridge University Press, 1985.

Testa, Italo. "Embodied Cognition, Habit, and Natural Agency in Hegel's Anthropology". En The Palgrave Hegel Handbook, Marina F. Bykova y Kenneth R. Westphal editores, 269-295. Londres: Palgrave, 2020.

. "Hegel's Naturalism, or Soul and Body in the Encyclopaedia". En Essays on Hegel's Philosophy of Subjective Spirit. David Stern editor. Albany: SUNY Press, 2012. "The Universal Form of Spirit: Hegel on Habit and Sociality". Hegel-Jahrbuch 1 (2010): 215-220.

\section{Sobre la autora}

Federica Gregoratto. Profesora asistente del Departamento de Filosofía de la Universität St. Gallen (St. Gallen, Suiza). Doctora en filosofía por Ca'Foscari University en Venecia, Italia. Fue investigadora postdoctoral del Cluster of Excellence "Normative Orders" en la 
Goethe-Universität de Francfort del Meno, Alemania, entre 2013 y 2015. Sus publicaciones se centran en distintos tópicos de la filosofía social y política, como son la filosofía del amor, la teoría crítica (especialmente Habermas y Adorno), el pragmatismo (Dewey y Addams), las teorías del reconocimiento y del poder, el género y los estudios interseccionales. Correo electrónico: federica.gregoratto@unisg.ch. 